\title{
Frequency of medication errors in an emergency department of a large teaching hospital in southern Iran
}

This article was published in the following Dove Press journal:

Drug, Healthcare and Patient Safety

II December 2014

Number of times this article has been viewed

\author{
Afsaneh Vazin' \\ Zahra Zamani' \\ Nahid Hatam ${ }^{2}$ \\ 'Department of Clinical Pharmacy, \\ Faculty of Pharmacy, ${ }^{2}$ School of \\ Management and Medical Information \\ Sciences, Shiraz University of Medical \\ Sciences, Shiraz, Iran
}

\begin{abstract}
This study was conducted with the purpose of determining the frequency of medication errors (MEs) occurring in tertiary care emergency department (ED) of a large academic hospital in Iran. The incidence of MEs was determined through the disguised direct observation method conducted by a trained observer. A total of 1,031 medication doses administered to 202 patients admitted to the tertiary care ED were observed over a course of 546 -hour shifts. Following collection of the data and analysis of the errors with the assistance of a clinical pharmacist, frequency of errors in the different stages was reported and analyzed in SPSS-21 software. For the 202 patients and the 1,031 medication doses evaluated in the present study, $707(68.5 \%)$ MEs were recorded in total. In other words, 3.5 errors per patient and almost 0.69 errors per medication are reported to have occurred, with the highest frequency of errors pertaining to cardiovascular $(27.2 \%)$ and antimicrobial $(23.6 \%)$ medications. The highest rate of errors occurred during the administration phase of the medication use process with a share of $37.6 \%$, followed by errors of prescription and transcription with a share of $21.1 \%$ and $10 \%$ of errors, respectively. Omission (7.6\%) and wrong time error (4.4\%) were the most frequent administration errors. The less-experienced nurses $(P=0.04)$, higher patient-to-nurse ratio ( $P=0.017)$, and the morning shifts $(P=0.035)$ were positively related to administration errors. Administration errors marked the highest share of MEs occurring in the different medication use processes. Increasing the number of nurses and employing the more experienced of them in EDs can help reduce nursing errors. Addressing the shortcomings with further research should result in reduction of MEs in EDs.
\end{abstract}

Keywords: medication errors, emergency department, frequency, patient safety

\section{Introduction}

Medication error (ME) is defined as failure in the treatment process causing harm to the patient. ${ }^{1,2}$

In addition to weakening the patients' confidence in medical services, MEs also impose substantial costs on the health sector. ${ }^{3}$ MEs prolong hospital stays by 2 days and increase the costs by $\$ 2,000-\$ 2,500$ per patient. ${ }^{4}$ To improve patients' health, it is essential to have adequate information about the epidemiology of MEs and adverse drug events in order to identify the root causes of failures in medication use processes. ${ }^{5}$ The main objective behind the ME reporting system is to determine how such errors can be reduced through improved patient safety services. ${ }^{6}$

An emergency department (ED) is among the most frequently visited departments of a hospital admitting only patients with critical and occasionally life-threatening diseases. $^{7}$ Sudden unpredictable events occurring in an ED have made this place an
Correspondence: Afsaneh Vazin Department of Clinical Pharmacy, Faculty of Pharmacy, Shiraz University of Medical Sciences, Shiraz, Iran

Tel +987112424128

Fax +98 7II 2424I26

Email vazeena@sums.ac.ir 
environment known for its high potential for MEs; as a matter of fact, nearly $3 \%$ of all undesirable hospital accidents are related to this department. ${ }^{8}$

Based on national data sources on MEs, Santell et al claimed in their article of 2004 that 11,000 MEs were reported to occur across 484 EDs over a 5-year period. $4.8 \%$ of these errors threatened the patients' health and caused five deaths. ${ }^{9}$

Given the significance of MEs in EDs and the inadequacy of data on the rate of these errors in Iran, the present study was conducted in order to assess ME rates, and types of MEs occurring in the ED in a teaching hospital in Iran.

\section{Method}

The present study was conducted from December 2013 to February 2014 in the tertiary care ED of the largest medical teaching hospital of Shiraz. This level of the department has five different units, including two surgical units, one neurological unit, and two internal medicine units with 40 beds overall.

Patients were selected according to random numbers and the ones who had spent less than 6 hours in the ED and those not receiving medications were excluded. In order to assess error rates, the disguised direct observation method was used by a trained observer (student of pharmacy). Observations were made directly and in disguise, with the department staff therefore unaware of the objectives of the study. The observer had previously received training in the ED for a month on the principles and methods of error collection by a clinical pharmacist. Observation shifts included two 6-hour morning and evening shifts, from 8 am to $2 \mathrm{pm}$ and then from $2 \mathrm{pm}$ to $8 \mathrm{pm}$. Observed shifts were almost equally divided between the morning shifts and the evening ones. The number of study participants was determined based on previous studies conducted in the ICU departments of two hospitals through the disguised direct observation method. ${ }^{10,11}$ At the confidence level of $95 \%$, ME prevalence rate of $44 \%$, error of $7 \%$, and $\alpha=0.05$, minimum sample size was calculated to be 194 . The data collection form was designed by a clinical pharmacist and then revised and approved by another independent clinical pharmacist.

Patients' demographic information, history of disease and medication, chief complaint, diagnosis, tests, and physicians' prescription (name of medications, dosage forms, medication doses, route of administrations, and dosages frequency) were recorded at the time of admission and the patients' conditions were monitored through to the end of each shift.
Meanwhile, the nurses' personal information, including biological gender, age, work experience, and other information such as the nurse-patient ratio and doses administered during the observation shift were recorded so as to calculate any potential association between these variables and MEs.

According to the classification and definition provided by the National Coordinating Council for Medication Error Reporting and Prevention system, MEs are generally categorized as prescription, transcription, dispensing, and administration errors. ${ }^{12}$ The present study investigates prescription, transcription, and administration errors.

The administration of medications was evaluated taking into account interactions, clinical and laboratory data, patient's current condition, allergies, disease and medication history, family history, and contraindications, and also considering the issues of right dosage, dosage frequency, dosage form, timing and route of administration, and appropriate monitoring of the medications using credible references. ${ }^{13-17}$ Ultimately, data on all observed doses were separately analyzed by a clinical pharmacist whose final opinion was then recorded in the error form.

In order for data analysis to be conducted, prescription errors, administration errors, and transcription errors were each separately entered into the statistical software. Entered data were processed using SPSS-21 software (SPSS, Chicago, IL). Percentage and mean \pm standard deviation were used to presenting the categorical and continuous variables, respectively.

\section{Results}

A total of 202 patients (118 males and 84 females) with a mean age of $53 \pm 18.17$ years were studied over a 3 -month period. The total number of prescriptions ordered for these patients $(n=202)$ was 1,031 doses with a mean number of $5.1 \pm 6.48$ medications prescribed to each patient. Therefore, 1,031 medication doses were observed over 54 8-hour shifts, $596(57.8 \%)$ of which were administered to men and 435 $(42.2 \%)$ to women (Table 1$)$. Of the total number of medications prescribed, the highest frequency pertained to the group of antimicrobial (24.3\%), cardiovascular (15.9\%), gastrointestinal (14.6\%), and anticoagulant (11.4\%) medications, in respective order (Table 2), with the highest frequency of errors pertaining to cardiovascular $(27.2 \%)$ and antimicrobial (23.6\%) medications. Most medications were administered orally (54.5\%) and through intravenous infusion (27.7\%) (Table 3).

Of the 1,031 medication doses, a total of $406(39.4 \%)$ were administered by male nurses and $625(60.6 \%)$ by 
Table I General characteristics of patients, nurses, work shifts, and weekly days during the study

\begin{tabular}{|c|c|c|c|c|}
\hline Variables & Frequency & Percentage & $\begin{array}{l}\text { Frequency } r \text { of } \\
\text { observed doses }\end{array}$ & $\begin{array}{l}\text { Percent of } \\
\text { observed doses }\end{array}$ \\
\hline \multicolumn{5}{|c|}{ Patient variables } \\
\hline \multicolumn{5}{|l|}{ Sex } \\
\hline Male & 118 & 58.4 & 596 & 57.8 \\
\hline Female & 84 & 41.6 & 435 & 42.2 \\
\hline \multicolumn{5}{|c|}{ Nurse variables } \\
\hline \multicolumn{5}{|l|}{ Sex } \\
\hline Male & 12 & 35.3 & 406 & 39.4 \\
\hline Female & 22 & 64.7 & 625 & 60.6 \\
\hline \multicolumn{5}{|c|}{ Level of education } \\
\hline Bachelor & 26 & 76.5 & 702 & 68.0 \\
\hline Diploma & 8 & 23.5 & 329 & 32.0 \\
\hline \multicolumn{5}{|c|}{ Work shifts and weekly days } \\
\hline \multicolumn{5}{|l|}{ Observed shifts } \\
\hline Morning & 29 & 53.7 & 673 & 65.3 \\
\hline Afternoon & 25 & 46.3 & 358 & 34.7 \\
\hline \multicolumn{5}{|c|}{ Days of the week } \\
\hline Saturday & 8 & 14.8 & 153 & 14.8 \\
\hline Sunday & 9 & 16.6 & 177 & 17.1 \\
\hline Monday & 7 & 13.0 & $14 \mid$ & 13.7 \\
\hline Tuesday & 9 & 16.6 & 162 & 15.7 \\
\hline Wednesday & 8 & 14.8 & 149 & 14.5 \\
\hline
\end{tabular}

Table 2 Number and percentage of pharmacological categories of observed doses $(n=1,031)$ during the study

\begin{tabular}{lll}
\hline Drug class & Number & $\begin{array}{l}\text { Percentage of } \\
\text { total reports }\end{array}$ \\
\hline Antimicrobials & 251 & 24.3 \\
Cardiovascular & 164 & 15.9 \\
Gastrointestinal & 150 & 14.6 \\
Anticoagulants & 117 & 11.4 \\
Hormones & 81 & 7.9 \\
CNS & 62 & 6.0 \\
Respiratory & 59 & 5.7 \\
Hematologic & 51 & 4.9 \\
Vitamins & 38 & 3.7 \\
Sedatives/analgesics & 30 & 2.9 \\
Electrolytes & 19 & 1.8 \\
Others & 9 & 0.9 \\
Total & 1,031 & 100 \\
\hline
\end{tabular}

Table 3 Route of administration of observed doses $(n=|, 03|)$ during the study

\begin{tabular}{lll}
\hline Route of administration & Number & Percentage \\
\hline Oral & 562 & 54.5 \\
Continuous infusion & 286 & 27.7 \\
Subcutaneous & 73 & 7.1 \\
Inhalation & 34 & 3.3 \\
Intravenous & 26 & 2.5 \\
Intramuscular & 19 & 1.8 \\
Topical & 17 & 1.7 \\
Intraocular & 14 & 1.4 \\
Total & $1,03 \mathrm{I}$ & 100 \\
\hline
\end{tabular}

female nurses. The mean age of nurses was $26.7 \pm 5.1$ years with a median work experience of $5 \pm 4$.7 years. The nurseto-patient ratio varied from 1:4 to 1:18 (Table 4 ). The less experienced nurses $(P=0.04)$, higher patient-to-nurse ratio $(P=0.017)$, and the morning shifts $(P=0.035)$ were positively related to administration errors.

Overall, of the 202 patients under study, 195 (96.5\%) had experienced at least one ME, and of the 1,031 medication doses observed, 707 (68.5\%) errors were recorded, making the rate of errors 3.5 per patient.

The frequency rate of errors is presented in Table 5 by general and categorical distinctions. The rate of MEs is reported as the frequency of errors occurred per every 100 doses observed. Administration errors had the highest rate (37.6\% of errors). In addition, of the variety of administration errors made, the highest frequency of errors

Table 4 Discrete demographic information of the patients $(n=202)$ and the nurses in the study of medication errors occurred at tertiary care emergency department of the study hospital

\begin{tabular}{|c|c|c|c|c|}
\hline Numeric variable & $\begin{array}{l}\text { Standard } \\
\text { deviation }\end{array}$ & Mean & Max & Min \\
\hline Age of the patients (years) & 18.17 & 53 & 97 & 5 \\
\hline Age of the nurses (years) & 5.1 & 26.7 & 45 & 21 \\
\hline Experience of nurses & 2.3 & $5^{*}$ & 21 & 0.5 \\
\hline Patient to nurse ratio & 3.1 & 11 & 18 & 4 \\
\hline
\end{tabular}


Table $\mathbf{5}$ Types of medication errors that occurred in tertiary level emergency department of the study hospital

\begin{tabular}{|c|c|c|}
\hline Type of errors & $\begin{array}{l}\text { Number of } \\
\text { errors }\end{array}$ & $\begin{array}{l}\text { Percentage of } \\
\text { errors }(N=I, 03 I)\end{array}$ \\
\hline \multicolumn{3}{|l|}{ Prescription errors } \\
\hline Wrong drug & 14 & $\mathrm{I} .4$ \\
\hline Omission & 8 & 0.8 \\
\hline Wrong frequency & 19 & 1.8 \\
\hline Wrong time & 16 & 1.6 \\
\hline Forgot to discontinue & 0 & 0 \\
\hline Contraindications & 0 & 0 \\
\hline Monitoring* & 53 & 5.1 \\
\hline Wrong dose (over) & 22 & 2.2 \\
\hline Wrong dose (under) & 8 & 0.8 \\
\hline Interactions & 37 & 3.6 \\
\hline Forget to order & 23 & 2.2 \\
\hline Others & 17 & 1.6 \\
\hline Total prescription error & 217 & 21.1 \\
\hline \multicolumn{3}{|l|}{ Transcription errors } \\
\hline Omission & 59 & 5.7 \\
\hline Wrong dose (over) & 13 & 1.3 \\
\hline Wrong dose (under) & 11 & I.I \\
\hline Wrong frequency & 7 & 0.7 \\
\hline Wrong time & 0 & 0 \\
\hline Forget to discontinue & 4 & 0.4 \\
\hline Others & 8 & 0.8 \\
\hline Total transcription error & 102 & 10.0 \\
\hline \multicolumn{3}{|l|}{ Administration errors } \\
\hline Omission & 78 & 7.6 \\
\hline Wrong time & 45 & 4.4 \\
\hline Wrong dosage form & 0 & 0 \\
\hline Wrong dose & 12 & 1.1 \\
\hline Wrong route & 4 & 0.4 \\
\hline Wrong rate & 33 & 3.2 \\
\hline Wrong preparation & 32 & 3.1 \\
\hline Administration of unordered drug & 8 & 0.8 \\
\hline Wrong technique & 23 & 2.2 \\
\hline Deteriorated drug & 0 & 0 \\
\hline Others & 153 & 14.8 \\
\hline Total administration error & 388 & 37.6 \\
\hline
\end{tabular}

Note: *Monitoring errors were calculated according to possible occurrences of the error; as a result, in calculating this error, the denominator was I 34 (number of occasions that required monitoring), not I,03I.

pertained to omission (7.6\%) and wrong time errors $(4.4 \%)$, in respective order.

It is a different case with monitoring errors. Of the 1,031 medication doses studied, only 134 required monitoring. The rate of monitoring errors is therefore $5.1 \%$.

Other administration errors pertained to the majority of oral medications administered to the patient by their companion, and, as already mentioned, oral administration was most frequently prescribed (54.5\%) and patients received most of their medications through this route. However, the present study took this error to occur in only one oral medication per patient - an error that occurred in 153 patients.

\section{Discussion}

Overall, in this study, the rate of MEs was found to be $68.5 \%$. The frequency of errors of administration, prescription, and transcription were $37.6 \%, 21.1 \%$, and $10.0 \%$, respectively. The high rate of administration errors compared to other errors is likely due to the high patient-nurse ratio in the hospital's tertiary care ED (at times, the number of patients in one unit even reached 18 with only one nurse responsible for the preparation and administration of medications). The patients were therefore exposed to a greater risk of medication administration errors.

According to the previous research, direct observation is a valuable method for detecting MEs, also yields reliable results. ${ }^{18-20}$ Because of the differences of definitions and the variety of error detection methods, it is difficult to compare statistics reported on the incidence of errors in different studies.

In a study conducted by Rothschild et al on MEs recorded by ED clinical pharmacists across four teaching hospitals, 17,320 medications prescribed for 6,471 patients were studied, 0.078 errors per patient, and 0.029 errors per medication were recorded..$^{21}$ The highest rate of errors pertained to dosing errors, drug omission, and wrong frequency errors. Rothschild et al concludes that, in most cases, the ED pharmacist can reduce potentially harmful MEs that might be imposed on the patient by the physician's prescription process, or the nurse's administration. ${ }^{21}$ The rate of errors observed in the mentioned study is lower than in the present study, in which 3.5 MEs occur per patient and 0.685 errors per medication. One of the reasons for the disparity of results is that MEs with a lower potential of harm to the patients were excluded from Rothschild et al's study, while, in the present study, any and all MEs were reported irrespective of their level of harm. Furthermore, in the mentioned study, the computerized physician order entry (CPOE) method was used in the three EDs under study, and all four departments benefited from the presence of an ED pharmacist, both of which can be major reasons for the lower rate of errors compared to the present study. The higher rates of errors during the administration stage found by the present study might be attributed to the failure to prepare medications in the central pharmacy of the hospital and also to the underestimated prescription errors caused by underestimated indication errors.

In a study using the direct observation method, 178 MEs were recorded for a total of 192 patients, with $59.4 \%$ of the patients having had at least one ME. ${ }^{22}$ In Patanwala et al's study, most errors had occurred in the prescription (53.9\%) and the administration (34.8\%) stages $;{ }^{22}$ however, there were 
fewer administration errors in comparison with our study. The researcher believes that recording prescription and transcription errors is easier, as the investigation and observation of the administration stage performed by the nurse might raise questions for the observer, and any interference with the nurse's job might distract her from her performance. ${ }^{22}$ It is therefore possible for the severity and incidence of MEs, particularly during the administration stage, to have been underestimated.

In a study conducted by Zeraatchi et al in the ED of Tehran teaching hospital, 500 patients and 1,291 medication doses were examined. ${ }^{23}$ Twenty-two percent of the patients had experienced at least one ME and 16 errors had occurred in every 100 doses. The highest rate of error occurred in the prescription stage (60.8\%) and pertained to wrong dose and frequency errors. Compared to the present study, the rate of prescription errors was higher. Zeraatchi et al believe the high rate of prescription errors in our country to be owing to our use of the traditional paper method for prescriptions, while in other countries, the CPOE system is used, which reduces some problems associated with physicians' poor handwriting and transcription errors and also may reduce prescription errors by issuing system warnings, in case of possible drug interactions and wrong dosage forms. Although we cannot fully rely on CPOE to prevent all types of errors, because the CPOE itself can contribute to occurrence of some potential errors. ${ }^{8}$

Nevertheless, prescription errors found in the present research were lower, which might be attributed to the observation of all morning, evening, and night shifts in Zeraatchi et al's study when, in the present study, only the morning and evening shifts were observed.

In a study conducted in the ED of Shariati teaching hospital of Tehran, 203 MEs (50.5\%) were recorded over 180 hours, with reported error rates being $33 \%$ for prescription, $63.6 \%$ for administration, and 3.4\% for monitoring. ${ }^{24}$ The higher rate of administration error is consistent with our study.

In another study conducted in an academic hospital on 94 ED nurses through the opinion survey method, the risk of MEs was found to be high among nurses; in fact, MEs were a major issue of ED's nurses. ${ }^{25}$ According to this study, the main causes of MEs occurring in the ED is the insufficient number of nurses, the lack of adequate knowledge on medications and fatigue due to huge workloads. In Ehsnai et al's study, only administration errors made by nurses were investigated, with the most common errors in this area being inappropriate infusion rates $(33.3 \%)$ and the administration of two medications instead of one (23.8\%). ${ }^{25}$ The disparity in rates of administration errors might be due to the different error collection method used in the mentioned study compared to the present study.

In our study, the highest rates of errors pertained to cardiovascular (27.2\%) and antimicrobial (23.6\%) medications. In Zeraatchi et al's study, the highest rate of errors pertained to cardiovascular medications, in particular, anticoagulants and thrombolytics (41.2\%) followed by antimicrobial agents $(37.7 \%) .{ }^{23}$ In the present study as well as Zeraatchi et al's study, the highest rates of errors pertained to cardiovascular and antimicrobial medications, which might be due to the high amount of cardiovascular patients' referral to our ED.

We consider the administration of prescribed oral medications by the patient's companion, administration error due to possible inadequacy of the companion's knowledge about the medication regimen especially when multiple drugs should be taken together, possible higher patient noncompliance in taking prescribed drugs leading to omission, and inadequate communication between nurses and patient companion because of the crowded nature of ED. All of these factors can lead to higher ME occurrence.

We encountered a number of limitations during the conducting of this study, including:

1) Although using the direct observation method for determining MEs was found to cause small negligible behavioral changes in the observed, results obtained are still valid and reliable. ${ }^{26,27}$ It is also possible for the observer to fail to record certain MEs over the course of the study; nevertheless, data from the present study as well as from previous research collected through the direct observation method, prove that common errors are missed less, comparing to voluntary reporting methods. ${ }^{6,10}$

2) Due to the patients' short hospital stays, we were therefore not able to evaluate the level of harm of MEs.

3) The impossibility of collecting data during overnight shifts due to the hospital's lack of cooperation with the observer for remaining in premises during these hours. This may be a significant concern, as sleep deprived staff or lower staffing at night may contribute to higher level of MEs; additional research about the impact of overnight shifts on ME rates are needed.

4) Probably many other factors (such as the training level of residents or nurses) can be contributing to MEs; however, further research is needed to identify them, and implementing actions to reduce the high rate of MEs.

In this study, $96.5 \%$ of patients had experienced at least one ME. So the rate of MEs is alarming, which requires 
implementing policies to prevent them. Among the various medication use processes, administration errors had the highest share of errors, and among administration errors, most common errors were the error of the administration of prescribed oral medications by the patient's companion, followed by omission and wrong time errors. It appears that the presence of a clinical pharmacist in the ED of hospitals for the purpose of providing consultation to the physicians and responding to the nurses' questions about medications can have a decisive role in the prevention and reduction of MEs. Further research to identify the flaws in the system and implementing interventions to block the MEs propagation at a very early stage are needed.

\section{Acknowledgment}

This study is the result of thesis number 92-01-05-7014 that is supported by Shiraz University of Medical Sciences.

\section{Disclosure}

The authors report no conflicts of interest in this work.

\section{References}

1. Williams D. Medication errors. J R Coll Physicians Edinb. 2007; 37(4):343.

2. Aronson JK, Ferner RE. Clarification of terminology in drug safety. Drug Saf. 2005;28(10):851-870.

3. Classen DC, Pestotnik SL, Evans RS, Lloyd JF, Burke JP. Adverse drug events in hospitalized patients. Excess length of stay, extra costs, and attributable mortality. JAMA. 1997;277(4):301-306.

4. Bates DW, Boyle DL, Vander Vliet MB, Schneider J, Leape L. Relationship between medication errors and adverse drug events. J Gen Intern Med. 1995;10(4):199-205.

5. Manasse H. Medication use in an imperfect world: drug misadventuring as an issue of public policy, part 1. Am J Health Syst Pharm. 1989;46(5):929-944.

6. Kopp BJ, Erstad BL, Allen ME, Theodorou AA, Priestley G. Medication errors and adverse drug events in an intensive care unit: direct observation approach for detection. Crit Care Med. 2006;34(2):415-425.

7. Taylor C, Benger J. Patient satisfaction in emergency medicine. Emerg Med J. 2004;21(5):528-532.

8. Pham JC, Story JL, Hicks RW, et al. National study on the frequency, types, causes, and consequences of voluntarily reported emergency department medication errors. J Emerg Med. 2011;40(5):485-492.

9. Santell J, Hicks R, Cousins D. Medication errors in emergency department settings -5 year review. Paper presented at: American Society of HealthSystems Pharmacists Summer Meeting; Jun 2004; Las Vegas, NV.
10. Vazin A, Delfani S. Medication errors in an internal intensive care unit of a large teaching hospital: a direct observation study. Acta Med Iran. 2012;50(6):425-432.

11. Vazin A, Fereidooni M. Determining frequency of prescription, administration and transcription errors in internal intensive care unit of Shahid Faghihi Hospital in Shiraz with direct observation approach. Iran J Pharm Sci. 2012;8(3):189-194.

12. National Coordinating Council for Medication Error Reporting and Prevention. Medication error index. Available from: http://www.nccmerp. org/medErroCatIndex. Accessed September 6, 2014.

13. Killion KH, Reily CH, Wickersham RM. Drug Facts and Comparison. USA: Wolters Kluwer Company; 2005.

14. Lacy CF, Armstrong LL, Goldman MP, Lance LL. Drug Information Handbook. 19th ed. Hudson, OH: Lexi-Comp; 2010.

15. Kimble MAK, Young LY, Kradjan WA, Guglielmo BJ, Alldredge BK, Corelli RL. Applied Therapeutics: The Clinical Use of Drugs. 8th ed. Philadelphia: Wolters Kluwer Company; 2005.

16. Schull PD. IV Drug Handbook. New York: McGraw-Hill Company; 2009.

17. Gahart BL. Intravenous Medications 2011: A Handbookfor Nurses and Health Professionals. 27th ed. Michigan: Mosby Company; 2011.

18. Capuzzo M, Nawfal I, Campi M, Valpondi V, Verri M, Alvisi R. Reporting of unintended events in an intensive care unit: comparison between staff and observer. BMC Emerg Med. 2005;5(1):3.

19. Flaatten H, Hevrøy O. Errors in the intensive care unit (ICU). Acta Anaesthesiol Scand. 1999;43(6):614-617.

20. Wilmer A, Louie K, Dodek P, Wong H, Ayas N. Incidence of medication errors and adverse drug events in the ICU: a systematic review. Qual Health Care. 2010;19(5):1-9.

21. Rothschild JM, Churchill W, Erickson A, et al. Medication errors recovered by emergency department pharmacists. Ann Emerg Med. 2010;55(6):513-521.

22. Patanwala AE, Warholak TL, Sanders AB, Erstad BL. A prospective observational study of medication errors in a tertiary care emergency department. Ann Emerg Med. 2010;55(6):522-526.

23. Zeraatchi A, Talebian M, Nejati A, Dashti-Khavidaki S. Frequency and types of the medication errors in an academic emergency department in Iran: the emergent need for clinical pharmacy services in emergency departments. J Res Pharm Pract. 2013;2(3):118.

24. Dabaghzadeh F, Rashidian A, Torkamandi H, et al. Medication errors in an emergency department in a large teaching hospital in Tehran. Iran J Pharm Res. 2013;12(4):937.

25. Ehsani SR, Cheraghi MA, Nejati A, Salari A, Esmaeilpoor AH, Nejad EM. Medication errors of nurses in the emergency department. JMed Ethics Hist Med. 2013;6:11.

26. Flynn EA, Barker KN, Pepper GA, Bates DW, Mikeal RL. Comparison of methods for detecting medication errors in 36 hospitals and skillednursing facilities. Am J Health Syst Pharm. 2002;59(5):436-446.

27. Dean B, Barber N. Validity and reliability of observational methods for studying medication administration errors. Am J Health Syst Pharm. 2001;58(1):54-59.
Drug, Healthcare and Patient Safety

\section{Publish your work in this journal}

Drug, Healthcare and Patient Safety is an international, peer-reviewed open-access journal exploring patient safety issues in the healthcare continuum from diagnostic and screening interventions through to treatment, drug therapy and surgery. The journal is characterized by the rapid reporting of reviews, original research, clinical, epidemiological and

\section{Dovepress}

post-marketing surveillance studies, risk management, health literacy and educational programs across all areas of healthcare delivery. The manuscript management system is completely online and includes a very quick and fair peer-review system. Visit http://www.dovepress.com/ testimonials.php to read real quotes from published authors. 